American Journal of Environmental Sciences 4 (6): 625-630, 2008

ISSN 1553-345X

(C) 2008 Science Publications

\title{
Vase Life Extension and Chlorophyll Fluorescence Yield of Bougainvillea Flower as Influenced by Ethanol to Attain Maximum Environmental Beautification as Ornamental Components
}

\author{
A.B.M. Sharif Hossain, Amru Nasrulhaq Boyce and Haji Mohamed A. Majid \\ Environmental Biotechnology and Physiology Laboratory, Institute of Biological Science, \\ Faculty of Science, University of Malaya, Kuala Lumpur 50603, Malaysia
}

\begin{abstract}
The study was conducted to investigate the effect of ethanol at different concentrations (ET) on bougainvillea flower longevity and delay senescence in storage condition. The treatments were water control, 2, 4, 8, 10, 20, 30, 40, 50 and 70\% ET. Flower longevity was 2 days more in 4, 8 and 10\% ethanol than water control and other concentrations of ethanol. Petal wilting and senescence were occurred 2 days later in 4, 8 and $10 \%$ ET than in water control. Percent petal's color changed was later in water 4, 8 and 10\% than in control, 2, 20, 30, 40, 50 and 70\% ET. Chlorophyll fluorescence intensity (photosynthetic yield) followed by time (ms) at different ethanol concentrations was higher in 4, 8 and $10 \%$ ET than in water control and other concentrations. Fo (lower fluorescence) was lower in 4, 8 and $10 \%$ ET than in water and other concentrations. However, Fm and Fv [(higher fluorescence and relative variable fluorescence $(\mathrm{Fm}-\mathrm{Fo})]$ were higher in 4, 8 and 10\% ET than in other ET concentrations. Fv/Fm (quantum yield or photosynthetic yield) was higher in 4, 8 and 10\% ET than in other ET concentrations. The result showed flower vase life was significantly affected by ethanol concentrations and longevity was higher in 4, 8 and $10 \%$ ethanol than in water control and other concentrations.
\end{abstract}

Key words: Bougainvillea flower, vase life, senescence, fluorescence, Fv/Fo

\section{INTRODUCTION}

Bougainvilleas are popular ornamental plants and used as official flowers in most areas with warm climates, including Australia, India, Malaysia, the Mediterranean region, Mexico, South Africa, Taiwan and the United States in Arizona, California, Florida, Hawaii and southern Texas. Bougainvillea is used to decorate fences and arbors with explosions of color in the house corridor, office and play ground. A bougainvillea tree can make guarding the entry or framing a window. Bougainvillea is a great vine for large containers to decorate hot patios and plazas. Bougainvillea is also used to create beautiful flowering bonsai specimens. Bougainvillea flower are dropped having a short vase life ${ }^{[1]}$. It has been reported that bougainvillea bracteoles were attractive at the end of 6 day observation period and dropped $32.2 \%$ with treated the STS (0.5 oz/Gallon) while, $100 \%$ was dropped in control tree.

${ }^{[2]}$ It has been reported that treatment with 4 and $6 \%$ ethanol increased the vase life of' carnation flowers and cultivars showed variable response to ethanol treatment with regards to vase life increment and delay in bud opening. They also mentioned that treatment with $4 \%$ ethanol inhibited ethylene production as well as sensitivity to ethylene and responsive to ethanol. The effectiveness of ethanol in extending vase life correlated closely with the longevity, ethylene production and ethylene sensitivity ${ }^{[2]}$.

Longevity of vase life is an important factor in consumer preference and considerable research has been carried out on the causes of carnation senescence ${ }^{[3,6]}$. Senescence of cut flowers is induced by several factors, e.g., water stress ${ }^{[7]}$, carbohydrate depletion $^{[8]}$, micro-organisms ${ }^{[9]}$. Ethanol has been found to be effective in increasing the vase life of carnation flowers by inhibiting ethylene biosynthesis ${ }^{[10,11]}$ as well as its action ${ }^{[11]}$. The concentration of ethanol effective in increasing vase life of carnation flowers ranges from $2 \%$ for an unknown cultivar to $8 \%^{[11]}$. Climacteric senescence can be prevented and hence longevity of the flowers increased with the use of various chemicals ${ }^{[12]}$ as a pre-treatment or in the vase solution, resulting in inhibition of either ethylene biosynthesis or ethylene action or both. It has been stated that acetaldehyde and ethanol, when applied as low concentration holding solutions both extend the vase life of cut carnation

Corresponding Author: A.B.M. Sharif Hossain, Environmental Biotechnology and Physiology Laboratory, Institute of Biological Science, Faculty of Science, University of Malaya, Kuala Lumpur 50603, Malaysia 
flowers by inhibiting the action of ACC synthase ${ }^{[13]}$. Treatment of cut carnation flowers with low concentrations of ethanol increases their vase life significantly ${ }^{[14,15]}$. Literatures are not available on this research project. That is why our interest has grown to develop vase life of bougainvillea flower. The aims of this project are to develop Bougainvillea flower quality (color development, longevity, expansions and delay senescence) newly by applying different ethanol concentrations and to improve the use of ornamental plant in the social and occasional functions.

\section{MATERIALS AND METHODS}

Site: The experimental site was University of Malaya campus, Kuala Lumpur, Malaysia

Plant material: Three-year-old Bougainvillea trees were used in this experiment for collecting flower samples. Bougainvillea flowers (purple) were collected from nursery, University of Malaya campus. The tree was $0.75 \mathrm{~m}$ of height and canopy length was $1.0 \mathrm{~m}$. The tree consisted of 4 branches. Flowers were harvested from each branch randomly.

Flower harvesting and measurement: Flower was harvested on January 20 2007. Flowers were weighed initially immediately after harvest and used for setting treatments.

Treatment setting: Treatments were set following completely blocked design. Each treatment was repeated by 4 replications. Total 40 flowers of 4 branches were collected for 10 treatments. The treatments were water control, $2 \%$ ethanol (ET), 4, 8, 10, 20, 30, 40, 50 and 70\% ET. Flower stems (petiole) were placed individually in distilled water immediately after cutting and sprayed to the petal and perianth containing different concentrations of ethanol solutions. The samples were placed at $28^{\circ} \mathrm{C}$ of room temperature.

Vase life, petal wilting, scar (color changed) and abscission evaluation: Vase life was observed by counting day. Flower status was observed everyday. Petal wilting was investigated. Percent petal wilting was calculated by observing the total petal area divided by wilted petal area multiplying by 100 . Color changing (petal scar) was determined by visual observation. After wilting phase, petal abscission was evaluated by observing petal abscised position.

Fresh and dry weight measurement: Fresh weight was measured immediately after harvest on 18 January
2007. Dry weight was measured after all flowers were abscised.

Chlorophyll fluorescence yield measurement: Chlorophyll fluorescence yield were measured by Hansatech Plant Efficiency Analyser. Petal was attached to the leafclip and kept for 30 min to maintain dark adaptation. Afterward, the leafclip was oriented with the side containing shutter plate. When light shine was applied on to the petal, the fluorescence signal was continued for $3 \mathrm{sec}$ and observed fluorescence yield or photosynthetic yield. It was represented by Fo, Fm, Fv and Fv/Fm (Photosynthetic yield or quantum yield). Where, $\mathrm{Fo}=$ Lower fluorescence, $\mathrm{Fm}=$ Higher fluorescence, $\mathrm{Fv}=$ Relative variable fluorescence $(\mathrm{Fm}$ Fo). Temperature $=28^{\circ} \mathrm{C}$. Time range $=10 \mu \mathrm{sec}^{-3}$.

Chlorophyll (carotinoid) content measurement: Chlorophyll (carotinoid) content was measured by Chlorophyll meter SPAD-502, Minolta Co. Japan which represented by SPAD value. The petal was inserted into the meter and measured SPAD value 5 times from different spot of a single petal.

Petal drop (abscission) measurement: Flowers were forced with air using fan. The flowers were kept in front of the table fan for $5 \mathrm{~min}$. The petal was dropped by air force and petal drop percent was calculated.

Design of experiment: The experimental design was Randomized Completely Block Design (RCBD). There were 4 replications and a total of 40 flowers used in the experiment. Mean separations were done by Duncan`s Multiple Range Test (DMRT).

\section{RESULTS AND DISCUSSION}

Wilting occurrence was shown on 6 DAT in water control, while it was shown in 8 DAT for 8 and $10 \%$ ET treated flower (Fig. 1). The wilting was started from 1 DAT for 50 and $70 \%$ ET, 2 DAT for 30 and $40 \%$ ET, 3 DAT for $20 \%$ ET, 6 DAT for $4 \%$ ET, 5 DAT for $2 \%$ ET and water (control), 7 DAT for 8 and $10 \%$ ET treated trees (Fig. 1).

In case of water control $100 \%$ wilting was done in 7 DAT, while it was found in 9DAT for 8 and 10\% ET treated flower. Percent petal senescence was earlier for water control, 2\% ET than 4, 8 and 10\% ET (Fig. 2). The petal senescence range was 3-12 days in different concentrations of ethanol. 


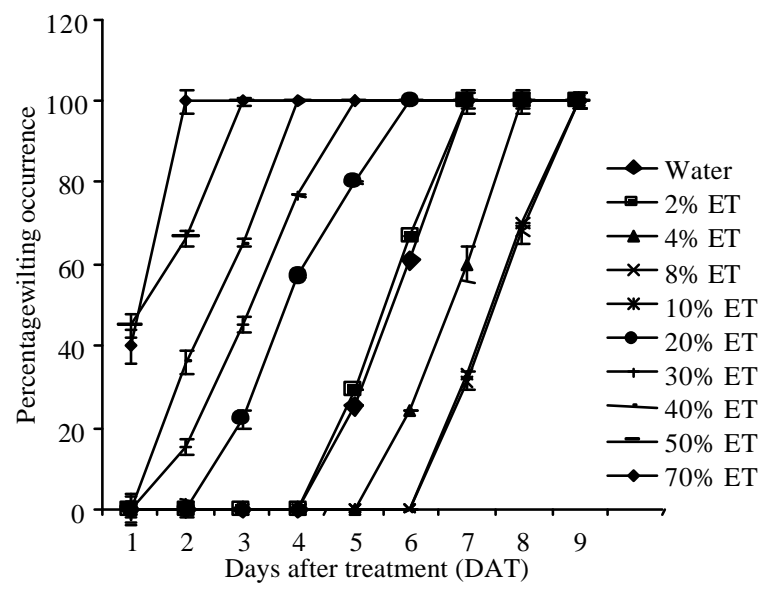

Fig. 1: Wilting occurrence followed by days after treatment at different ethanol concentrations. Bars represent SE $(n=4)$

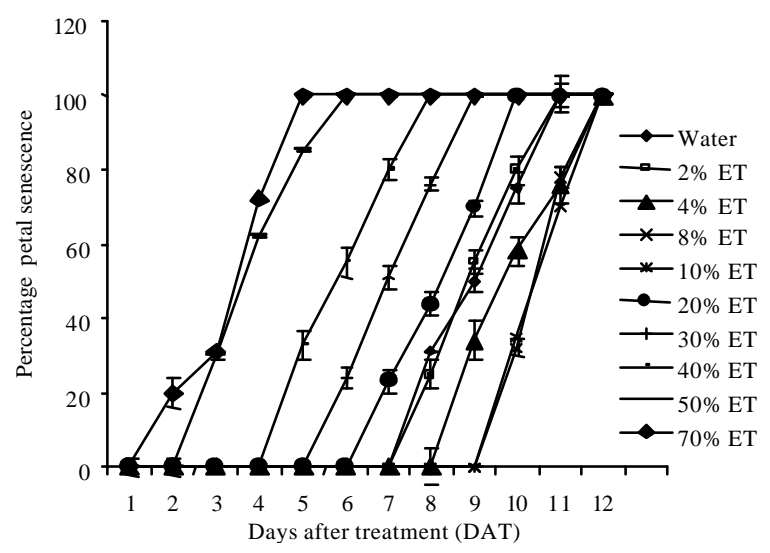

Fig. 2: Petal senescence followed by days after treatment at different ethanol concentrations. Bars represent SE $(n=4)$

The senescence order was $70<50<30<20<$ water control and $2<4,<8$ and $10 \%$ ET. Percent petal discoloration was earlier in water, 2, 4, 20, 30, 40, 50 and $70 \%$ ET than 4, 8 and $10 \%$ ET (Fig. 3).

The similar increasing (day) trend was found in case of all ET treated flowers. Petal discoloration started in 4 DAT for water control and completed $(100 \%)$ in 11 DAT, whereas, it was started in 5 DAT and completed $(100 \%)$ in 11 DAT for 8 and $10 \%$ ET treated flowers.

Chlorophyll fluorescence intensity (yield) followed by time (ms) was different at different ethanol concentrations (Fig. 4).

Chlorophyll fluorescence intensity was found fluctuated trend in case of all treatments. Fluorescence

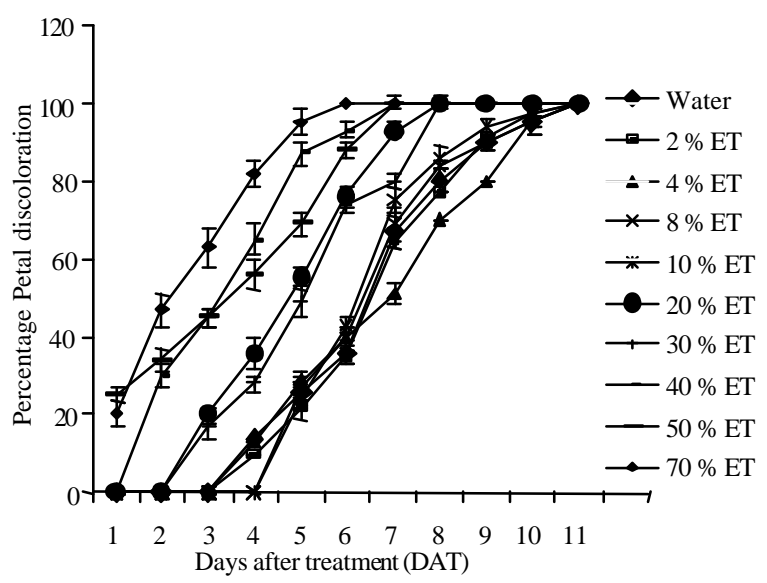

Fig. 3: Petal discoloration followed by days after treatment at different ethanol concentrations. Bars represent SE $(n=4)$

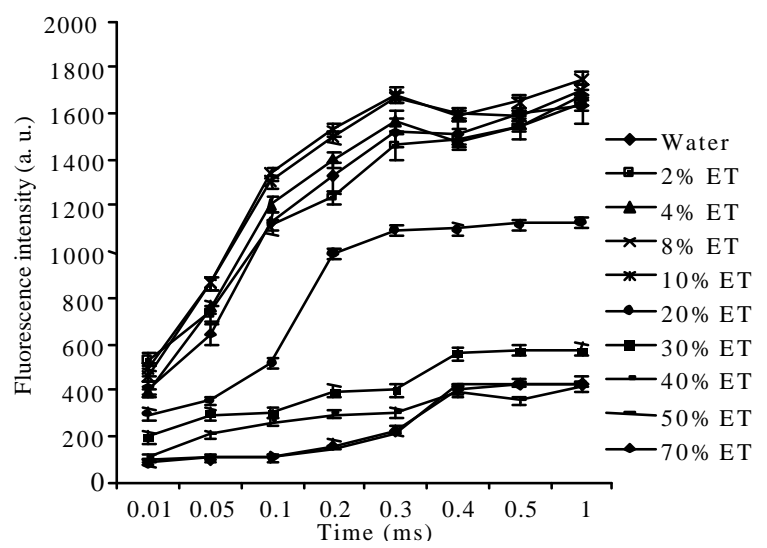

Fig. 4: Chlorophyll fluorescence intensity (yield) followed by time (ms) at different ethanol concentrations. Fo $=$ Lower fluorescence, $\mathrm{Fm}=$ Higher fluorescence, $\mathrm{Fp}=$ Intermediate fluorescence. Temperature $=28^{0} \mathrm{C}$. Bars represent $\operatorname{SE}(n=4)$

was higher in 8 and $10 \%$ ET than in other treatments. Fo $=$ Lower fluorescence, $\mathrm{Fm}=$ Higher fluorescence, $\mathrm{Fp}=$ Intermediate fluorescence were higher in 4, 8 and $10 \%$ ET than in other concentrations followed by time ranging from $0.01-1 \mathrm{~ms}$. Fm and $\mathrm{Fv}=$ Relative variable fluorescence $(\mathrm{Fm}-\mathrm{Fo})$ were higher in water control, 2, 4,8 and $10 \%$ ET than in other treatments followed by time ranging from $2 \mathrm{~ms}-3$ (Fig. 5).

Among the treatments, Fm and Fv were higher in 4, 8 and $10 \%$ ET than in water control, 2 and $4 \%$ ET. Optimum quantum yield [(Photosynthetic yield $(\mathrm{Fv} / \mathrm{Fm})]$ was higher in 4,8 and $10 \%$ ET than in other concentrations (Fig. 6). 


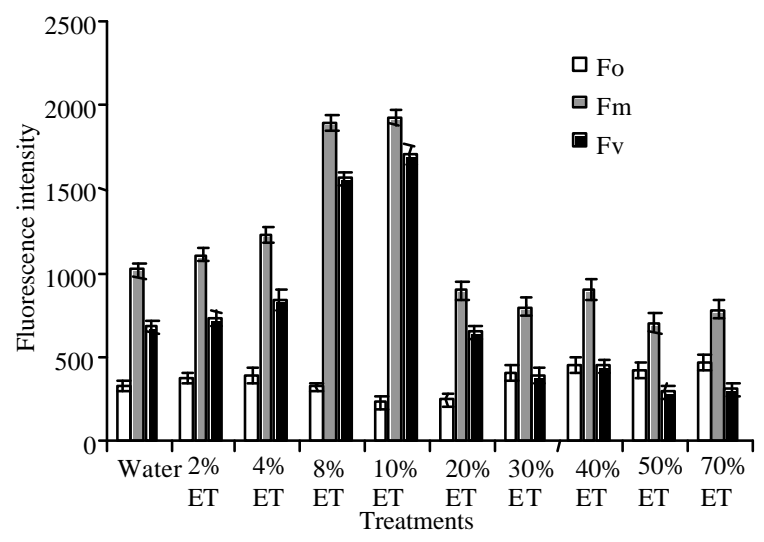

Fig. 5: Chlorophyll (carotene) fluorescence intensity (yield) followed by days after treatment at different ethanol concentrations. Fo $=$ Lower fluorescence, $\quad \mathrm{Fm}=$ Higher fluorescence, $\mathrm{Fv}=$ Relative variable fluorescence $(\mathrm{Fm}-\mathrm{Fo})$. Temperature $=28^{\circ} \mathrm{C}$. Bars represent SE $(n=4)$. Time range: $2 \mathrm{~m} \mathrm{sec}^{-3}$

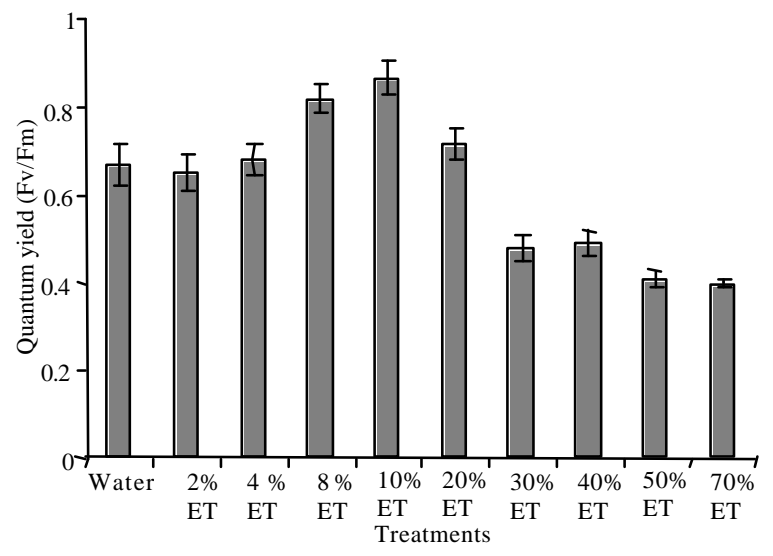

Fig. 6: Photosynthetic yield (Optimum quantum yield, $\mathrm{Fv} / \mathrm{Fm}$ ) followed by days after treatment at different ethanol concentrations. Fo $=$ Lower fluorescence, $\quad F m=$ Higher fluorescence, $\mathrm{Fv}=$ Relative variable fluorescence $(\mathrm{Fm}-\mathrm{Fo})$. Temperature $=28^{\circ} \mathrm{C}$. Bars represent SE $(n=4)$

Vase life was found 1 day more for $4 \%$ ET and 2 days more in 8 and $10 \%$ ET than water control and $2 \%$ ET treated flowers (Table 1). The vase life was gradually decreasing as $6,5,4,2,1$ and 0.5 day following the order of 8 and 10>4> water control and $2>20>30$ and $40>50$ and $70 \%$ ET. Fresh weight (before wilting) was measured and there was not significantly difference among all treatments (Table 1). Dry weight was measured after abscission. Dry weight significantly
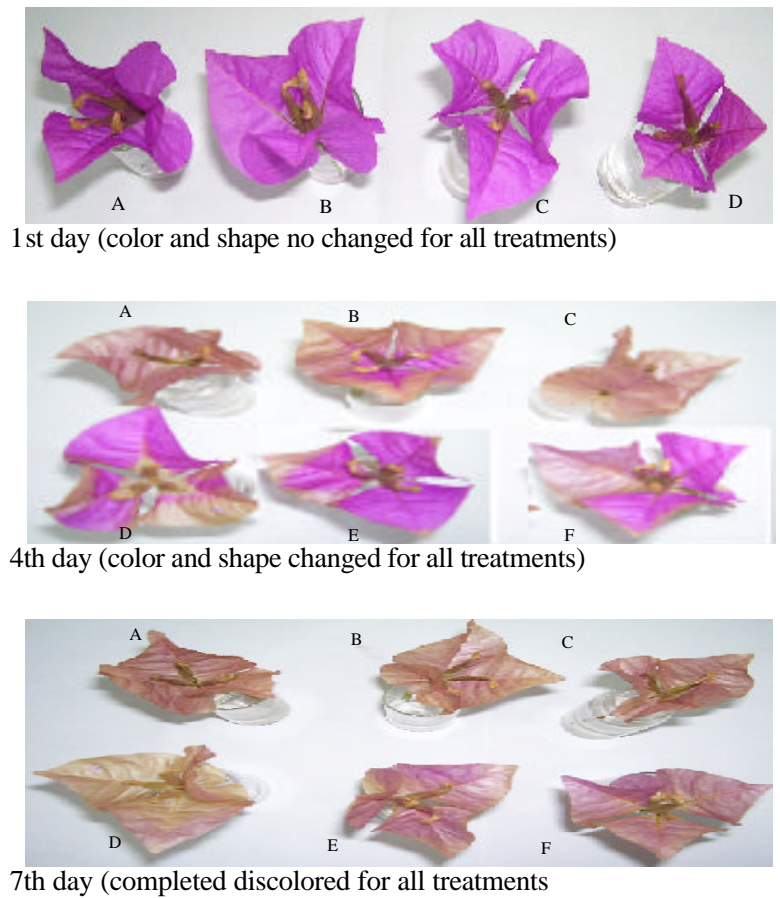

Fig. 7: Photo shows the flower architecture and senescence (shape and color) after treatment. A: Water control; B: $2 \%$ ethanol; C: $4 \%$ ethanol; D: $8 \%$ ethanol; E: $10 \%$ ethanol; F: $70 \%$ ethanol

reduced in case of all treatment but more significantly reduced at 40, 50 and $70 \%$ ET treated flower. Fresh and dry weight ratio was lower at 2, 4, 8 and $10 \%$ ET than water control, 20, 30, 40, 50 and 70\% ET (Table 1). Petal was shed $33.3 \%$ at 4,8 and $10 \%$ ET, $66.6 \%$ at water control, 2 and 20 and $100 \%$ at $30,40,50$ and $70 \%$ ET.

Initially chlorophyll (carotinoid) content (SPAD value) was almost same at different treatments. However, finally it was higher 8 and $10 \%$ ET other than all treatments. Figure 7 shows the different flower structures and color changing after treatment application at different stages.

The results show that ethanol is effective as ethylene inhibiting component in bougainvillea flower. It was found that the more effective was 4, 8 and $10 \%$ ethanol. Results indicate that sensitivity to ethylene develops several days after flower opening such that ethanol only has a limited ability to delay vase life as well as petal senescence. It was reported that ethylene was the major coordinator of senescence in many flowers ${ }^{[16]}$. It has been stated that ethanol, when applied as low concentration holding solutions both extend the vase life of cut carnation flowers ${ }^{[13]}$. 
Am. J. Environ. Sci., 4 (6): 625-630, 2008

Table 1: Fresh and dry weight of bougainvillea flower as affected by different concentrations of ethanol Mean \pm SE $(n=4)$. FW: Fresh weight, DW: Dry weight, Means followed by the common letters in column are not significantly different at the 5\% level by Duncan`s Multiple Range Test (DMRT)

\begin{tabular}{|c|c|c|c|c|c|c|c|}
\hline \multirow[b]{2}{*}{ Treatments } & \multirow[b]{2}{*}{$\begin{array}{l}\text { Fresh weight } \\
\text { (g) (Initial) g }\end{array}$} & \multirow{2}{*}{$\begin{array}{l}\text { Dry weight }(\mathrm{g}) \\
\text { after abscission } \\
\text { (Final) g }\end{array}$} & \multirow[b]{2}{*}{$\begin{array}{l}\text { Ratio } \\
(\mathrm{FW} / \mathrm{DW})\end{array}$} & \multirow[b]{2}{*}{$\begin{array}{l}\text { Vase life } \\
\text { (Day) }\end{array}$} & \multirow{2}{*}{$\begin{array}{l}\text { Petal } \\
\text { abscission } \\
(\text { drop })(\%)\end{array}$} & \multicolumn{2}{|c|}{$\begin{array}{l}\text { Chlorophyll (carotinoid) } \\
\text { content (SPAD value) }\end{array}$} \\
\hline & & & & & & Initial & Final \\
\hline Water & $0.57 \pm 0.10 \mathrm{a}$ & $0.301 \pm 0.05 b$ & $1.89 \pm 0.20 \mathrm{a}$ & $4.5 \pm 0.32 \mathrm{c}$ & $66.3 \pm 5.8 b$ & $3.8 \pm 0.5 a$ & $0.3 \pm 0.02 b$ \\
\hline $2 \%$ Ethanol & $0.62 \pm 0.12 \mathrm{a}$ & $0.345 \pm 0.06 c$ & $1.79 \pm 0.11 \mathrm{a}$ & $4.5 \pm 0.34 \mathrm{c}$ & $66.3 \pm 5.6 b$ & $3.6 \pm 0.4 \mathrm{a}$ & $0.3 \pm 0.02 b$ \\
\hline $4 \%$ Ethanol & $0.48 \pm 0.09 a$ & $0.261 \pm 0.05 b$ & $1.83 \pm 0.13 \mathrm{a}$ & $5.5 \pm 0.33 d$ & $33.3 \pm 3.8 \mathrm{a}$ & $3.7 \pm 0.3 \mathrm{a}$ & $0.2 \pm 0.01 \mathrm{a}$ \\
\hline $8 \%$ Ethanol & $0.66 \pm 0.08 \mathrm{a}$ & $0.395 \pm 0.05 \mathrm{c}$ & $1.67 \pm 0.12 \mathrm{a}$ & $6.5 \pm 0.45 d$ & $33.3 \pm 3.3 \mathrm{a}$ & $3.7 \pm 0.3 \mathrm{a}$ & $0.5 \pm 0.02 \mathrm{c}$ \\
\hline $10 \%$ Ethanol & $0.62 \pm 0.11 \mathrm{a}$ & $0.393 \pm 0.05 c$ & $1.57 \pm 0.15 \mathrm{a}$ & $6.5 \pm 0.38 \mathrm{~d}$ & $33.3 \pm 3.3 \mathrm{a}$ & $3.8 \pm 0.3 \mathrm{a}$ & $0.6 \pm 0.02 c$ \\
\hline $20 \%$ Ethanol & $0.51 \pm 0.06 \mathrm{a}$ & $0.275 \pm 0.04 b$ & $1.85 \pm 0.16 \mathrm{a}$ & $2.5 \pm 0.27 b$ & $66.3 \pm 00 b$ & $3.6 \pm 0.4 \mathrm{a}$ & $0.2 \pm 0.01 \mathrm{a}$ \\
\hline $30 \%$ Ethanol & $0.60 \pm 0.11 \mathrm{a}$ & $0.310 \pm 0.04 \mathrm{~b}$ & $1.93 \pm 0.23 \mathrm{a}$ & $1.5 \pm 0.22 \mathrm{a}$ & $100 \pm 00 \mathrm{c}$ & $3.8 \pm 0.3 \mathrm{a}$ & $0.2 \pm 0.01 \mathrm{a}$ \\
\hline $40 \%$ Ethanol & $0.67 \pm 0.10 \mathrm{a}$ & $0.181 \pm 0.04 \mathrm{a}$ & $3.70 \pm 0.28 b$ & $1.5 \pm 0.12 \mathrm{a}$ & $100 \pm 00 \mathrm{c}$ & $3.6 \pm 0.4 \mathrm{a}$ & $0.2 \pm 0.01 \mathrm{a}$ \\
\hline $50 \%$ Ethanol & $0.55 \pm 0.08 \mathrm{a}$ & $0.132 \pm 0.03 a$ & $4.16 \pm 0.37 \mathrm{c}$ & $0.5 \pm 0.04 \mathrm{a}$ & $100 \pm 00 \mathrm{c}$ & $3.7 \pm 0.5 \mathrm{a}$ & $0.1 \pm 0.005 a$ \\
\hline $70 \%$ Ethanol & $0.64 \pm 0.09 \mathrm{a}$ & $0.097 \pm 0.02 \mathrm{a}$ & $6.60 \pm 0.51 d$ & $0.5 \pm 0.04 \mathrm{a}$ & $100 \pm 00 \mathrm{c}$ & $3.8 \pm 0.5 \mathrm{a}$ & $0.05 \pm 0.005 a$ \\
\hline
\end{tabular}

They also mentioned that low concentration of ethanol apparently decreased the formation of ethylene by inhibiting the action of ACC synthase. Ethanol has been found to be effective in increasing. The vase life of carnation flowers has been increased using ethanol by inhibiting ethylene biosynthesis ${ }^{[10,11]}$ as well as its $\operatorname{action}^{[11]}$.

In our results, we found more effective in case of 4 , 8 and $10 \%$ ET. Similar results to us were found by some researchers. The concentration of ethanol was effective in increasing vase life of carnation flowers ranges from $2 \%^{[10]}$ to $8 \%^{[11]}$ for the different cultivars. This variation in response could be due to differences in cultivar sensitivity to ethylene ${ }^{[17]}$. Treatment of cut carnation flowers with low concentrations of ethanol increased their vase life significantly ${ }^{[17,18]}$. Quantum yield (Fv/Fm) was higher in 4,8 and $10 \%$ ET than in other concentrations. It is meant the stress or effect of 4 , 8 and $10 \%$ ET is less on bougainvillea flower. That is why it is effective for flower longevity.

\section{CONCLUSION}

Our result showed that it was possible to extend vase life of bougainvillea using 4, 8 and $10 \%$ ethanol by causing delay senescence. Low concentration of ethanol decreased the formation of ethylene by inhibiting the action of ACC synthase as a result over all flowers (wilting, abscission, scar and color changing) were affected physiologically.

Though literatures were found regarding concentrations of ethanol $(2-8 \%)$ were effective in extending vase life of cut carnation flowers. However, in this experiment our result is highlighted the similar effect in bougainvillea flower by attaining maximum environmental beautification as ornamental components.

\section{ACKNOWLEDGEMENT}

The researchers are grateful to Musammath Maimuna Akter for assistance of sample preparation and computing data in this research.

\section{REFERENCES}

1. Cameron, C.A., M.S. Reid and G.W. Hickman, 1981. Using STS to prevent flower shattering in potted flowering plants-progress report. Flower and nursery report for commercial grower. Cooperative Extension, University of California, pp: 6.

2. Pun, U.K., R.N. Rowe, J.H. Rowarth, M.F. Barnes, C. Dawson and J.A. Oheyes, 1999. Influence of ethanol on climacteric senescence in five cultivars of carnation. N. Z. J. Crop Horticult. Sci., 27: 69-77. http://www.royalsociety.org.nz/ Site/publish/Journals/nzjchs/1999/9.aspx.

3. Reid, M.S., J.L. Paul, M.B. Farhoomand, A.M. Kofranek and G.L. Staby, I980. Pulse treatments with the silver thiosulphate complex extend the vase life of cut carnations. J. Am. Soc. Horticult. Sci., 105: 25-27.

4. Reid, M.S., A.M. Kofranek and S.T. Besemer, 1983. Postharvest handling of carnations. Acta Horticult., 141: 235-238.

5. Cook, E.L. and V.J. Staden, 1983. Senescence of cut carnation flowers: Ovary development and $\mathrm{CO}_{2}$ fixation. Plant Growth Reg., 1: 221-232. DOI: 10.1007/BF00024716.

6. Menguc, A. and E. Usta, 1994. Research on the effects of silver thiosulphate plus sucrose pretreatment on the cold storage period and post storage vase life of cut flowers of carnation cv. Astor havested at different maturities. Acta Horticult., 368: 802-807. 
7. Sankat, C.K. and S. Mujaffar, 1994. Water balance in cut anthurium flowers in storage and its effect on quality. Acta Horticult., 368: 723-732. http://www.actahort.org/members/showpdf?booknr arnr=368_86.

8. Ketsa, S., 1989. Vase life characteristics of inflorescences of dendrobium 'Pompadour. J. Horticult. Sci., 64: 611-615. http://www.fao.org/ agris/search/display.do?f=./1990/v1621/GB901004 3.xml;GB9010043.

9. Witte, Y.D. and W.G. Van Doom, 1991. The mode of action of bacteria in the vascular occlusion of cut rose flowers. Acta Horticult., 298: 165-167. http://www.fao.org/agris/search/display.do?f=./199 3/v1916/NL9305897.xml;NL9305897.

10. Heins, R.D. and N. Blakely, 1992. Influence of ethanol on ethylene biosynthesis and flower senescence of cut carnation. Sci. Horticult., 13: 361-369. http://www.fao.org/agris/ search/display.do?f=./1981/v703/XE8083030.xml; XE8083030.

11. Wu, M.J., Z. Lorenzo, M.E. Saltveit and M.S. Reid, 1992. Alcohols and carnation senescence. HortScience, 27: 136-138. http://cat. inist.fr/?aModele $=$ afficheN\&cpsidt $=5117620$.

12. Staby, G.L., R.M. Basel, M.S. Reid and L.L. Dodge, 1993. Efficacies of commercial antiethylene products for fresh cut flowers. HortTechnology, 3: 199-202. http://www.fao.org/ agris/search/display.do?f=./1994/v2018/US943241 8.xml;US9432418.
13. Heins, R.D., 1980. Inhibition of ethylene synthesis and senescence in carnation by ethanol. J. Am. Soc. Horticult. Sci., 105: 141-144.

14. Podd, L.A. and J.V. Staden, 2004. The role of ethanol and acetaldehyde in flower senescence and fruit ripening. J. Plant Growth Reg., 26: 183-189.

15. Podd, L.A. and J.V. Staden, 1998. The role of ethanol and acetaldehyde in flower senescence and fruit ripening-a review. Plant Growth Reg., 26: 183-189. http://www.springerlink.com/ content/vx8v8t8544451587/.

16. Nichols, R., 1968. The response of carnation (Dianthus caryophyllus) to ethylene. J. Horticult. Sci., 43: 335-349.

17. Serrano, M., F. Romojaro, J.L. Casas and M. Acosta, 1991. Ethylene and polyamine metabolism in climacteric and non-climacteric carnation flowers. HortScience, 26: 894-896. http:// cat.inist.fr/?aModele $=$ afficheN\&cpsidt $=5386577$.

18. Mayak, S. and T. Triosh, 1993. Unusual ethylenerelated behaviour in senescing flowers of the carnation Sandrosa. Physiol. Plantarum, 88: 420-426. http://www3.interscience.wiley. com/journal/119295799/abstract?CRETRY=1\&SR $\mathrm{ETRY}=0$. 